\title{
Sjogrens SS-A52 Antibody Measurement
}

National Cancer Institute

\section{Source}

National Cancer Institute. Sjogrens SS-A52 Antibody Measurement. NCI Thesaurus.

Code C120661.

The determination of the Sjogrens SS-A52 antibody present in a sample. 